\title{
Case Files of the Medical Toxicology Fellowship at the Toxikon Consortium in Chicago: Cocaine-Associated Wide-Complex Dysrhythmias and Cardiac Arrest- Treatment Nuances and Controversies
}

\author{
Ejaaz A. Kalimullah, MD, Sean M. Bryant, MD
}

Cook County-Stroger Hospital, Toxikon Consortium; Department of Emergency Medicine, University of Illinois at Chicago, Chicago, IL

\section{CASE PRESENTATION}

A 19-year-old woman was brought by ambulance to the emergency department (ED) from a police holding cell. Less than 3 hours earlier, the patient had been a passenger in a car stopped for a traffic violation. As the police officer approached the car, the patient was noted to hurriedly stuff 2 plastic bags containing a white powdery substance into her mouth. On questioning, it was reported that the packets contained cocaine. Less than an hour after being taken to the police station, the patient was witnessed to have a generalized seizure. Emergency medical services (EMS) were immediately summoned.

Upon EMS arrival, the seizure activity had ceased. The patient was reportedly unresponsive and noted to have a narrow-complex supraventricular tachycardia. The paramedics provided oxygen by a non-rebreather mask, established intravenous (IV) access, and prepared the patient for rapid transport to the ED. En route to the $\mathrm{ED}$, the patient's rhythm evolved into a wide-complex tachycardia. Due to suspected ventricular tachycardia (VT) and ongoing hemodynamic instability, the patient underwent synchronized cardioversion at $100 \mathrm{~J}$ with immediate conversion to sinus tachycardia just minutes prior to ED arrival.

\section{What is the pharmacological basis of acute cocaine intoxication?}

Cocaine intoxication typically produces a sympathomimetic toxidrome marked by tachycardia, hypertension, hyperthermia, diaphoresis, and increased psychomotor activity [1]. The pathophysiology of cocaine is driven by its sympathetic nervous system effects, central nervous system (CNS) stimulation, and local anesthetic effects. In addition to its effects on the vasomotor center, cocaine produces tachycardia and hypertension by inhibiting the reuptake of both norepinephrine and epinephrine. Catecholamine stimulation of peripheral postsynaptic $\alpha_{1}$-adrenergic receptors helps mediate the hypertensive response, while binding at postsynaptic $\beta_{1}$-receptors is implicated in producing tachycardia. In the CNS, the enhanced release of excitatory amino acids plays a key role in mediating the seizures, agitation, and hyperthermia noted in severe cocaine poisoning. In addition, reuptake blockade of the biogenic amines norepinephrine, epinephrine, dopamine, and serotonin are also involved in producing the CNS and neuropsychiatric effects of cocaine [1-3].

The dysrhythmogenic properties of cocaine, as well as its electrocardiographic manifestations, derive in part from cocaine's effects on cardiac sodium and potassium channels. Similar to other local anesthetics, cocaine blocks neuronal sodium channels, impeding sodium conductance during phase 0 of the cardiac action potential. This produces QRS widening in a manner analogous to Vaughn-Williams type IA and IC antidysrhythmic agents. Cocaine can also cause QTc prolongation via blockade of cardiac potassium efflux channels [1-2].

\section{What are the cardiovascular manifestations of acute cocaine intoxication?}

A review of the diverse acute and delayed clinical manifestations of cocaine exposure is beyond the scope of the current discussion.

Keywords: cocaine, lidocaine, dysrhythmia, seizure, cardiac arrest Note: There was no outside funding of any kind used for this study. Corresponding Author: Sean M. Bryant, MD, 1900 West Polk, 10th Floor, Chicago, IL 60612. Email: sbryant@ccbh.org 


\section{Table 1: Dysrhythmias Associated With Cocaine Use}

Sinus bradycardia

Sinus tachycardia

Supraventricular tachycardia

Bundle-branch block

Complete heart block

Accelerated idioventricular rhythm

Ventricular tachycardia

Ventricular fibrillation

Asystole

Torsade de pointes

Brugada pattern

With regard to its acute cardiovascular manifestations, commonly encountered clinical effects include tachycardia and hypertension. Larger doses of cocaine, producing plasma concentrations of approximately $3 \mathrm{mg} / \mathrm{L}$ or more, demonstrate negative inotropic effects and depress myocardial systolic and diastolic function [4,5]. These effects are most likely mediated by cocaine's action at cardiac sodium channels [5-7]. Furthermore, the effects of cocaine on adrenergic tone and cardiac ion channels can precipitate a variety of dysrhythmias (Table 1) [8]. In many cases, the cardiac dysrhythmias ascribed to cocaine have occurred in the context of concurrent derangements such as hypotension, hypoxemia, seizures, metabolic acidosis, myocardial infarction, or other altered myocardial substrates [8].

Beyond its ability to precipitate dysrhythmias, cocaine is capable of producing vasoconstriction in the coronary vasculature, as well as the cerebral, pulmonary, and mesenteric vascular beds $[1,3,8]$. In the acute setting, cocaine can precipitate myocardial ischemia and infarction by a variety of mechanisms. Beyond the catecholamine-driven increase in myocardial oxygen consumption and coronary vasospasm, cocaine promotes platelet aggregation and impairs endogenous thrombolysis. These more immediate effects can be particularly problematic when combined with accelerated atherosclerosis due to chronic cocaine use $[1,2,8]$.

Not surprisingly, given their similar pathogenic mechanisms, cerebrovascular thrombosis, transient ischemic attacks, pulmonary vascular thrombosis, and lung infarction have been described following cocaine use. Intracerebral hemorrhage, subarachnoid hemorrhage, and aortic dissection have also been described, likely resulting from cocaine's ability to increase vascular shear forces $[1,3,8]$.

\section{CASE CONTINUATON}

In the ED, the patient was unresponsive, but breathing spontaneously and noted to have persistent sinus tachycardia. The pupils were dilated bilaterally. The patient's skin was cool and clammy. Due to persistent tachycardia and the reported history of cocaine ingestion with prior seizure activity, $2 \mathrm{mg}$ of IV lorazepam was administered. During the administration of lorazepam, the patient's condition deteriorated to "agonal breathing" followed within 5 minutes by cardiac arrest, initially with pulseless electrical activity (PEA) and then asystole. Chest compressions were initiated, the patient was endotracheally intubated, and $1 \mathrm{mg}$ of epinephrine was administered 3 times during the following 8-10 minutes; no atropine was administered. Following the return of spontaneous circulation, the patient was hypotensive with a systolic blood pressure ranging from 40 to $60 \mathrm{mmHg}$, which was treated with infusions of dopamine $(20 \mu \mathrm{g} / \mathrm{kg} / \mathrm{minute})$ and norepinephrine (15 $\mu \mathrm{g} /$ minute). An EKG (Figure 1) was performed during the peri-arrest period, which demonstrated a rate of 91 beats/minute, a PR interval of $226 \mathrm{msec}$, QRS duration of 172 $\mathrm{msec}$, and QTc interval of $488 \mathrm{msec}$. The patient was also given $50 \mathrm{~g}$ of activated charcoal by nasogastric tube.

At this time, our toxicology consultation service was contacted by phone via our regional poison control center. The patient's last recorded vital signs prior to poison center consultation were: temperature $36.7^{\circ} \mathrm{C}$, pulse $90 /$ minute, respirations $16 /$ minute (ventilator rate), and systolic blood pressure of approximately 100 $\mathrm{mmHg}$ with dopamine and norepinephrine drips as noted above. An arterial blood gas done after return of spontaneous circulation demonstrated: $\mathrm{pH}$ 6.77, $\mathrm{pCO}_{2} 69 \mathrm{mmHg}, \mathrm{pO}_{2} 292 \mathrm{mmHg}, \mathrm{HCO}_{3}{ }^{-}$ $9 \mathrm{mEq} / \mathrm{L}$, and an oxygen saturation of $97 \%$ with a $\mathrm{F}_{\mathrm{I}} \mathrm{O}_{2}$ of $100 \%$. Given the reported EKG findings, a recommendation for the immediate administration of 2 ampules of $\mathrm{NaHCO}_{3}$ was made along with a request for repeating vital signs frequently and increasing the minute ventilation delivered to the patient.

While initial consultation was still underway, the patient was again found to have no measurable blood pressure or palpable pulse. Due to wide-complex dysrhythmia with PEA cardiac arrest, the emergency physician was advised to administer IV boluses of hypertonic $\mathrm{NaHCO}_{3}$ until QRS narrowing occurred, in addition to usual advanced cardiac life support (ACLS) interventions. Further discussion of resuscitation interventions was deferred at this point.

\section{What is the basis for using sodium bicarbonate in cocaine-induced wide-complex dysrhythmias?}

The use of hypertonic $\mathrm{NaHCO}_{3}$ as an antidote for cocaineinduced QRS widening has been established in a number of animal studies as well as clinical practice. As noted above, QRS widening is driven by cocaine's blockade of cardiac sodium channels. Although the clinical use of bicarbonate in the treatment of cocaine-induced wide-complex dysrhythmias had been described in the medical literature as early as 1983 [9], it was in 1991 that Beckman et al. published their paper detailing the electrocardiographic effects of sodium bicarbonate therapy in a canine model [6]. Using sequential $5 \mathrm{mg} / \mathrm{kg}$ IV cocaine boluses coupled with a continuous infusion $(0.2 \mathrm{mg} / \mathrm{kg} / \mathrm{minute})$ to produce toxicity, the comparative effects of single bolus $\mathrm{NaHCO}_{3}(2 \mathrm{mEq} / \mathrm{kg})$ versus $5 \%$ dextrose were assessed. They found that bicarbonate therapy was 


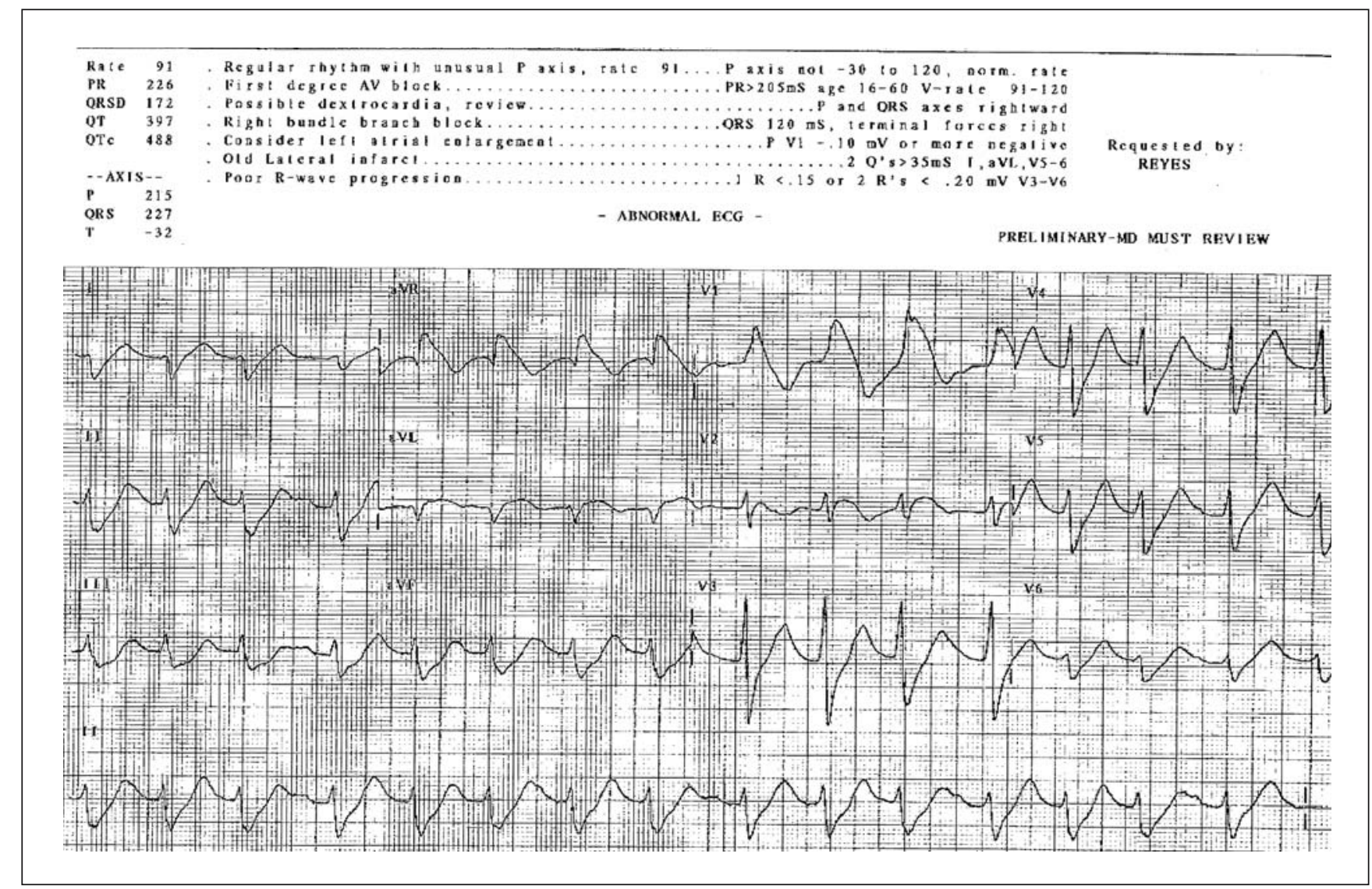

Figure 1: EKG obtained in ED near the time of initial cardiac arrest, with a rate of 91 beats/min, QRS width of 172 msec, and QTc interval of $488 \mathrm{msec}$. Note the prominent $R$ wave in $a V_{R}$.

able to promptly narrow the QRS width, similar to its effects in type IA antidysrhythmic and tricyclic antidepressant poisoning. Bicarbonate did not affect the PR, QT, or QTc intervals and, in their model, did not reverse the hemodynamic effects of cocaine. This contrasts somewhat with the canine study published by Wilson and Shelat [7]. Their study utilized 3 successive boluses of $7 \mathrm{mg} / \mathrm{kg}$ cocaine followed by single bolus $\mathrm{NaHCO}_{3}(2 \mathrm{mEq} / \mathrm{kg})$ or placebo. Wilson and Shelat observed QRS narrowing after bicarbonate administration as well as sustained increases in cardiac output and ventricular contractile function.

Several human case reports support the efficacy of sodium bicarbonate as a therapeutic intervention in the setting of cocaine-induced wide-complex arrhythmias and cardiac arrest. Kerns et al. [10] and Wang [11] published independent case series describing the successful use of $\mathrm{NaHCO}_{3}$ to treat wide-complex dysrhythmias resulting from severe cocaine poisoning. Described patients included individuals who sustained asystolic cardiac arrest and pulseless VT. A recent case report from Spain highlights the use of $\mathrm{NaHCO}_{3}$ in the resuscitation of a patient with asystolic cardiac arrest and subsequent wide-complex Brugada pattern [12].

Given that cocaine's inhibition of sodium conductance is worsened at higher heart rates and is increased at lower $\mathrm{pH}$, hypertonic sodium bicarbonate likely improves conductance by both sodium loading and amelioration of the systemic acidosis that often accompanies severe cocaine poisoning $[11,13]$. However, a canine study comparing the effects of $2 \mathrm{mEq} / \mathrm{kg}$ $\mathrm{NaHCO}_{3}(1 \mathrm{mEq} / \mathrm{mL})$ versus sodium loading with $2 \mathrm{mEq} / \mathrm{kg} \mathrm{NaCl}$ $(1 \mathrm{mEq} / \mathrm{mL})$ did not demonstrate any significant reversal of cocaine-induced QRS widening with sodium loading alone [14]. In accordance with the experimental data and demonstrated clinical efficacy, contemporary discussions of ACLS emphasize the role of sodium bicarbonate in the treatment of wide-complex dysrhythmias evolving soon after cocaine exposure $[15,16]$.

\section{What are potential adverse effects from the use of sodium bicarbonate?}

The administration of large amounts of sodium bicarbonate may cause excessive alkalemia, hypokalemia, hypocalcemia, hypernatremia, and hyperosmolarity [17-19]. Exogenous sodium bicarbonate may also cause the accumulation of carbon dioxide. Carbon dioxide is able to rapidly diffuse across cell membranes and thus may result in a paradoxical intracellular acidosis $[20,21]$. The latter phenomenon could theoretically exert a negative inotropic effect on myocardial function. 


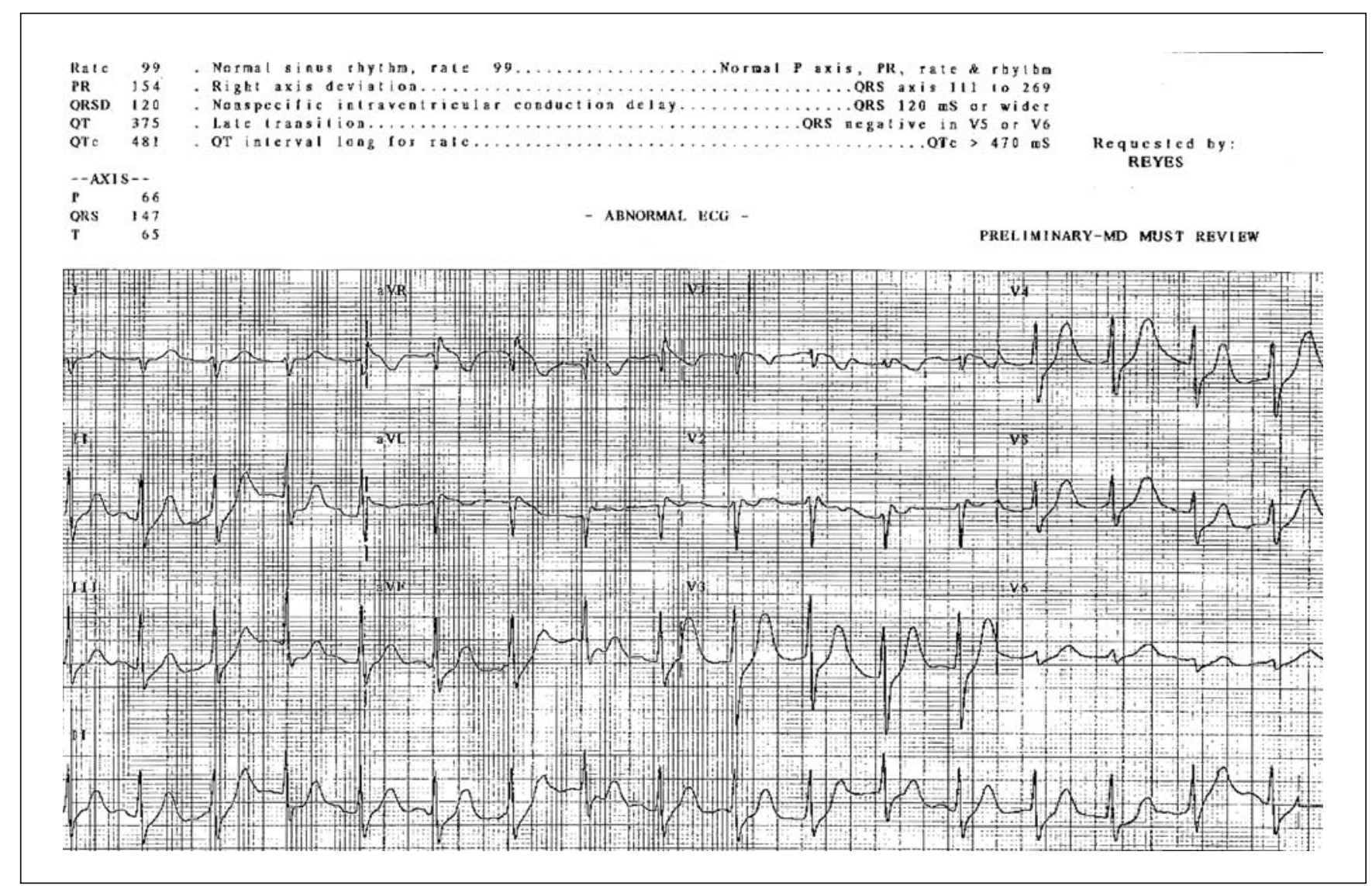

Figure 2: EKG obtained after resuscitation from the second cardiac arrest, demonstrating a rate of 99 beats/min, QRS of 120 msec, and QTC of $481 \mathrm{msec}$. QRS narrowing and reduction in the amplitude of the $a V_{R} R$ wave are apparent.

\section{CASE CONTINUATION}

The patient's recurrent cardiac arrest was marked by wide-complex PEA with a rate $<100$ beats/minute and brief periods of VT. Over the ensuing 25-minute resuscitation, the patient received 6 ampules of $\mathrm{NaHCO}_{3}(50 \mathrm{mEq}$ each) along with epinephrine as per typical ACLS dosing. The patient once again had return of spontaneous circulation. A continuous infusion of sodium bicarbonate $(150 \mathrm{mEq} / \mathrm{L})$ in $5 \%$ dextrose at $150 \mathrm{~mL} /$ hour had been initiated, and the patient's systolic blood pressure was roughly 70 $\mathrm{mmHg}$ on dopamine and norepinephrine drips. A repeat EKG (Figure 2) was obtained, revealing a rate of 99 beats/minute, PR of $154 \mathrm{msec}$, QRS of $120 \mathrm{msec}$, and QTc of $481 \mathrm{msec}$. Available labs included an EMIT urine qualitative drug screen, which was positive only for cocaine metabolites. The ED service was asked for a full set of repeat vital signs, including rectal temperature, and was instructed to treat any hyperthermia with active cooling measures. Frequent assessment of QRS width was recommended, with a goal of maintaining the QRS $\leq 120 \mathrm{msec}$ via boluses of $\mathrm{NaHCO}_{3}$. The ED service was specifically advised not to merely rely on the bicarbonate infusion that had been started. Repeat arterial blood gas and basic metabolic panel were requested in addition to serial $\mathrm{CPK}, \mathrm{CK}-\mathrm{MB}$, and troponin. The repeat blood gas, done $<2$ hours after return of spontaneous circulation, showed: $\mathrm{pH} 7.35, \mathrm{pCO}_{2}$ $47 \mathrm{mmHg}, \mathrm{pO}_{2} 140 \mathrm{mmHg}$, and $\mathrm{HCO}_{3}^{-} 25.7 \mathrm{mEq} / \mathrm{L}$. Two hours after the second ED cardiac arrest, the patient's vital signs on ICU admission were: $\mathrm{T} 39.0^{\circ} \mathrm{C}$, BP $124 / 47 \mathrm{mmHg}$, respirations $16 /$ minute, $\mathrm{SaO} 298 \%$ on $100 \% \mathrm{~F}_{\mathrm{I}} \mathrm{O}_{2}$. The ICU service was advised to initiate active cooling, core body temperature monitoring, and to administer benzodiazepines for sedation if hemodynamically tolerated. At this point, information regarding the role of antidysrhythmic therapy was requested by the ICU service.

\section{What is the basis for the use of lidocaine in cocaine-induced wide-complex dysrhythmias?}

Although lidocaine possesses fast sodium channel-blocking properties, lidocaine is a type IB antidysrhythmic and does not prolong the QRS interval or cardiac action potential duration. Type IB drugs have their highest affinity for inactivated sodium channels, which are found at the end of depolarization, during early repolarization, and during ischemia resulting in partial myocardial depolarization. Unlike cocaine, lidocaine has rapid on-off binding kinetics and is thought to bind to sodium channels briefly during late systole, when the channels are largely inactivated. These effects were illustrated in a series of elegant ex vivo 
experiments using guinea pig and canine cardiac tissues [22-24]. These investigations provided experimental proof for the ability of lidocaine to antagonize cocaine-induced QRS widening and negative dromotropic effects. In addition, the experiments done by Bauman's group strongly supported the concept of competitive binding between lidocaine and cocaine at the sodium channel [22-24].

Other investigators have attempted to assess lidocaine's ability to reduce the lethality of severe cocaine poisoning in whole animal models. In their randomized, controlled, and blinded study, Heit et al. utilized a murine model to assess the effect of lidocaine pretreatment $(32 \mathrm{mg} / \mathrm{kg})$ on ataxia, seizures, and death following intraperitoneal cocaine (40-110 mg/kg) administration. Although lidocaine significantly increased the incidence of ataxia and seizures, there was a significant reduction in cocaine-induced lethality [25]. It may be that lidocaine suppresses cocaine's cardiotoxicity at the cost of additive or synergistic central nervous system (CNS) toxicity. Nonetheless, lidocaine is suggested as a potential therapy for cocaine-induced wide-complex arrhythmias in most textbooks of clinical toxicology and in discussions of toxicological ACLS $[1,3,13,15]$.

\section{What are the potential adverse effects of using lidocaine in the setting of severe acute cocaine toxicity?}

As noted above, concerns have been raised regarding potential enhancement of CNS toxicity by the use of lidocaine to treat severe acute cocaine poisoning. In 1991, Derlet et al. published a study that compared groups of rats given isolated doses of either 30 or $40 \mathrm{mg} / \mathrm{kg}$ intraperitoneal lidocaine, escalating doses of cocaine ranging from 10 to $50 \mathrm{mg} / \mathrm{kg}$, and the treatment group that received varying simultaneous injections of the same lidocaine and cocaine doses. The authors reported significant increases in the incidences of both seizures and death when lidocaine and cocaine were given in combination at doses that did not produce seizures or death when each drug was given in isolation at such doses [26]. In a more recent rodent study, Barat and Abdel-Rahman administered IV injections of $5 \mathrm{mg} / \mathrm{kg}$ or 20 $\mathrm{mg} / \mathrm{kg}$ of cocaine or lidocaine alone, and compared these groups to rats given the same doses combined in equal proportions. While $5 \mathrm{mg} / \mathrm{kg}$ of either lidocaine or cocaine alone did not cause seizures, the simultaneous administration of $5 \mathrm{mg} / \mathrm{kg}$ each of lidocaine and cocaine precipitated seizures with a frequency equal to that following $20 \mathrm{mg} / \mathrm{kg}$ of cocaine alone. In addition, rats given $20 \mathrm{mg} / \mathrm{kg}$ each of lidocaine and cocaine had 100\% incidences of seizures and mortality. Although diazepam pretreatment in this combination group successfully lowered the incidence of death to $0 \%$, the rate of seizures remained at $100 \%$ [27].

Although the human retrospective study by Shih et al. is often cited in support of the safety of lidocaine administration, the population studied received lidocaine in the setting of cocaine-associated myocardial infarction [28]. The most common reasons for lidocaine administration were dysrhythmia prophylaxis and suppression of premature ventricular contractions. Out of 27 patient charts available for review, only 8 individuals were treated with lidocaine due to VT, and a single individual received lidocaine following cardiac arrest. Furthermore, most of the patients reported cocaine use $>4$ hours prior to presentation, with 3 patients having used cocaine at least 72 hours previously. While the relevance of this study with regard to the therapy of wide-complex dysrhythmias in the setting of severe acute cocaine intoxication may be questionable, it is notable that there were no bradydysrhythmias, seizures, fatalities, episodes of sustained VT, or ventricular fibrillation (VF) in the lidocaine-treated patients [28]. While acknowledging the limitations of this study, a contemporary article on toxicological ACLS nonetheless asserted that "there is a large amount of unpublished clinical experience with the use of lidocaine for treatment of cocaine-associated VT and VF, and no adverse effects have been reported" [15].

\section{Is there any evidence for the use of amiodarone to treat cocaine-induced wide-complex dysrhythmias?}

Amiodarone is currently frequently employed in the treatment of wide-complex arrhythmias and refractory ventricular fibrillation/tachycardia [29]. However, the efficacy of this agent in the treatment of cocaine-induced dysrhythmias is essentially undefined. Since amiodarone blocks $\beta$-adrenergic receptors in addition to sodium, potassium, and calcium channels, theoretical concerns exist regarding its safety in the setting of cocaine exposure [1]. A recent randomized, controlled mouse study utilizing relatively high-dose intraperitoneal cocaine $(110 \mathrm{mg} / \mathrm{kg})$ failed to demonstrate any difference in seizure incidence or mortality following amiodarone pretreatment $(40 \mathrm{mg} / \mathrm{kg})$ [30].

\section{CASE CONTINUATION}

According to the patient's companions, she had ingested $>2 \mathrm{~g}$ of cocaine. During the first 24 hours following admission, the patient was administered 2 more ampules of sodium bicarbonate due to QRS widening slightly beyond $140 \mathrm{msec}$. Neither lidocaine nor amiodarone was utilized during the patient's hospital course. The patient did not experience any further cardiac arrests and her acid-base status remained normal. The patient's vasopressor requirements rapidly declined and the ongoing bicarbonate drip rate was reduced. The rectal temperature peaked at $39.9^{\circ} \mathrm{C}$ during the first day, and was successfully treated using sedation with intermittent lorazepam boluses and cooling with a floor fan to blow air over a wet cooling blanket. By the second hospital day, the patient's temperature had normalized, all vasopressors had been discontinued, and her EKG demonstrated only mild sinus tachycardia with a QRS of $70 \mathrm{msec}$ and QTc of $472 \mathrm{msec}$. Acidbase status remained normal and the $\mathrm{NaHCO}_{3}$ infusion was stopped. The patient developed mild rhabdomyolysis with a peak CPK level of approximately 12,000 U/L. Serial cardiac biomarkers were significant for increased CK-MB and troponin I $(1.8 \mathrm{ng} / \mathrm{mL})$ levels without ST-segment elevation. By the fourth hospital day, spontaneous eye opening and respiratory activity were evident. 
However, the patient failed to display any purposeful movement and electroencephalography on the eighth day only showed diffuse slowing. Ultimately, the patient could not be extubated and required tracheostomy with subsequent discharge to a chronic ventilator facility 3 weeks post-admission.

\section{CONCLUSION}

Manifestations of cocaine poisoning range widely from mild sympathomimetic overdrive to life-threatening seizures, hyperthermia, and cardiac dysrhythmias. While supportive care, including the judicious use of benzodiazepines and cooling measures, is paramount, the management of cocaine-associated wide-complex dysrhythmias and cardiac arrest regularly includes sodium bicarbonate boluses in order to narrow QRS length. When confronted with refractory dysrhythmias, one must weigh the benefits and risks of further antidysrhythmic therapies. Lidocaine is frequently recommended when sodium bicarbonate fails. While animal studies regularly demonstrate CNS toxicity (seizures) and variable effects on mortality with the use of lidocaine, it has demonstrated effectiveness in suppressing cardiotoxicity associated with cocaine poisoning [22-27]. While experience with using lidocaine may exist, literature support of its use in the patient with cocaineinduced wide-complex dysrhythmias is sparse at best $[15,28]$. Amiodarone has not been proven to be a viable alternative to sodium bicarbonate or lidocaine, possesses promiscuous pharmacological activity, and cannot be generally recommended for cocaine-associated dysrhythmias in the absence of data supporting its safety and efficacy $[1,30]$.

Remembering Paracelsus's words that all things are poisons certainly includes the current "evidence-based" antidotal therapy utilized to manage poisonings. Picking your poison (i.e., drug) to manage severe cocaine-induced cardiotoxicity may not be as straightforward as some would believe.

The authors have no potential financial conflicts of interest to report.

\section{REFERENCES}

1. Hoffman RS. Cocaine. In: Flomenbaum NE, Goldfrank LR, Hoffman RS, Howland MA, Lewin NA, Nelson LS, eds. Goldfrank's Toxicologic Emergencies. 8th ed. New York: McGrawHill; 2006.

2. Goldfrank LR, Hoffman, RS. The cardiovascular effects of cocaine. Ann Emerg Med 1991;20:165-175.

3. Hollander JE, Hoffman, RS. Cocaine. In: Ford MD, Delaney KA, Ling LJ, Erickson T, eds. Clinical Toxicology Philadelphia: W.B. Saunders; 2001.

4. Fraker TD Jr, Temesy-Armos PN, Brewster PS, Wilkerson RD. Mechanism of cocaine-induced myocardial depression in dogs. Circulation 1990;81:1012-1016.

5. Pitts WR, Vongpatanasin W, Cigarroa JE, Hillis LD, Lange RA. Effects of the intracoronary infusion of cocaine on left ventricular systolic and diastolic function in humans. Circulation 1998;97:1270-1273.

6. Beckman KJ, Parker RB, Hariman RJ, Gallastegui JL, Javaid JI, Bauman JL. Hemodynamic and electrophysiological actions of cocaine. Effects of sodium bicarbonate as an antidote in dogs. Circulation 1991;83:1799-1807.

7. Wilson LD, Shelat C. Electrophysiologic and hemodynamic effects of sodium bicarbonate in a canine model of severe cocaine intoxication. J Toxicol/Clin Toxicol 2003;41:777-788.

8. Lange RA, Hillis LD. Cardiovascular complications of cocaine use. N Engl J Med 2001;345:351-358.

9. Jonsson S, O'Meara M, Young JB. Acute cocaine poisoning: importance of treating seizures and acidosis. Am J Med 1983;75:1061-1064.

10. Kerns W, Garvey L, Owens J. Cocaine-induced wide complex dysrhythmia. J Emerg Med 1997;15:321-329.

11. Wang RY. pH-dependent cocaine-induced cardiotoxicity. Am J Emerg Med 1999;17:364-369.

12. Ortega-Carnicer J, Bertos-Polo J, Gutiérrez-Tirado C. Aborted sudden death, transient Brugada pattern, and wide QRS dysrrhythmias after massive cocaine ingestion. J Electrocardiol 2001;34:345-349.

13. Albertson TE, Chan A, Tharratt RS. Cocaine. In: Shannon MW, Borron SW, Burns MJ, eds. Haddad and Winchester's Clinical Management of Poisoning and Drug Overdose. 4th ed. Philadelphia: Saunders Elsevier; 2007.

14. Parker RB, Perry GY, Horan LG, Flowers NC. Comparative effects of sodium bicarbonate and sodium chloride on reversing cocaine-induced changes in the electrocardiogram. J Cardiovasc Pharmacol 1999;34:864-869.

15. Albertson TE, Dawson A, de Latorre F, Hoffman RS, Hollander JE, Jaeger A, et al. TOX-ACLS: toxicologic-oriented advanced cardiac life support. Ann Emerg Med 2001;37:S78-90.

16. 2005 American Heart Association Guidelines for Cardiopulmonary Resuscitation and Emergency Cardiovascular Care. Part 10.2: Toxicology in ECC. Circulation 2005;112:Suppl IV-126-IV-132.

17. Lin CJ, Chen YC, Chen HH, Liu CC, Wu CJ. Life-threatening ventricular arrhythmia induced by hypokalemia during sodium bicarbonate infusion. South Med J 2008;101:215-216.

18. Moon PF, Gabor L, Gleed RD, Erb HN. Acid-base, metabolic, and hemodynamic effects of sodium bicarbonate or tromethamine administration in anesthetized dogs with experimentally induced metabolic acidosis. Am J Vet Res 1997;58:771-776.

19. Proudfoot AT, Krenzelok EP, Vale JA. Position paper on urine alkalinization. J Toxicol/Clin Toxicol 2004;42:1-26.

20. Ritter JM, Doktor HS, Benjamin N. Paradoxical effect of bicarbonate on cytoplasmic pH. Lancet. 1990;335:1243-1246.

21. Kette F, Weil MH, von Planta M, Gazmuri RJ, Rackow EC. Buffer agents do not reverse intramyocardial acidosis during cardiac resuscitation. Circulation 1990;81:1660-1666.

22. Winecoff AP, Hariman RJ, Grawe JJ, Wang Y, Bauman JL. Reversal of the electrocardiographic effects of cocaine by 
lidocaine. Part 1. Comparison with sodium bicarbonate and quinidine. Pharmacotherapy 1994;14:698-703.

23. Grawe JJ, Hariman RJ, Winecoff AP, Fischer JH, Bauman JL. Reversal of the electrocardiographic effects of cocaine by lidocaine. Part 2. Concentration-effect relationships.

Pharmacotherapy 1994;14:704-711.

24. Liu D, Hariman RJ, Bauman JL. Cocaine concentrationeffect relationship in the presence and absence of lidocaine: evidence of competitive binding between cocaine and lidocaine. J Pharmacol Exp Ther 1996;276:568-577.

25. Heit J, Hoffman RS, Goldfrank LR. The effects of lidocaine pretreatment on cocaine neurotoxicity and lethality in mice. Acad Emerg Med 1994;1:438-442.

26. Derlet RW, Albertson TE, Tharratt RS. Lidocaine potentiation of cocaine toxicity. Ann Emerg Med 1991;20:135-138.
27. Barat SA, Abdel-Rahman MS. Cocaine and lidocaine in combination are synergistic convulsants. Brain Res 1996;742:157-162.

28. Shih RD, Hollander JE, Burstein JL, Nelson LS, Hoffman RS, Quick AM. Clinical safety of lidocaine in patients with cocaine-associated myocardial infarction. Ann Emerg Med 1995;26:702-706.

29. 2005 American Heart Association Guidelines for Cardiopulmonary Resuscitation and Emergency Cardiovascular Care. Part 7.2: Management of cardiac arrest. Circulation 2005;112:Suppl IV-58-IV-66.

30. Dewitt CR, Cleveland N, Dart RC, Heard K. The effect of amiodarone pretreatment on survival of mice with cocaine toxicity. J Med Toxicol 2005;1:11-18. 